\title{
ПРЕСЛАВИЗМЫ В АПОКРИФИЧЕСКИХ ВОПРОСАХ АПОСТОЛА ВАРФОЛОМЕЯ*
}

Апокрифические Вопросы апостола Варфоломея (далее - Варф) написаны, как предполагается, на греческом языке в III веке. В течение столетий они были переведены на латинский и старославянский языки, а до нашего времени дошли в двух греческих, двух латинских и шести старославянских списках.

Текст памятника состоит из пяти глав. Первая глава повествует о сошествии Иисуса в ад и выводе им оттуда Адама и всех праведников. Этот сюжет в апокрифической литературе очень популярен и дошел до нас в нескольких писаниях, сохранившихся также в старославянских переводах, напр., в гомилии Епифания Кипрского о сошествии Христа в ад ${ }^{1}$ или в Евангелии Никодима². Во второй главе Варфоломей спрашивает Богородицу о событиях, которые предшествовали воплощению Сына Божия. В третьей главе Иисус показывает апостолам апокалиптическую бездну, а в четвертой главе - связанного Сатану. В славянских списках отсутствует пятая глава, в которой Иисус говорит о смертных грехах и уходит. Части этой главы, вероятно, более поздние дополнения.

В соответствии с дошедшими до нас списками, можно предполагать, что на старославянский язык был переведен только текст памятника в рамках глав $1,1-4,13$. Подлинный греческий образец старославянского перевода до нас не дошел, но из двух до нас дошедших греческих списков к славянскому ближе (с текстологической точки зрения) список Австрийской национальной библиотеки в Вене - Cod. hist. gr. 67, XIII века (далее ВенаГр) ${ }^{3}$. Этот список содержит тексты глав 1,28-5,11. Второй список, возникший уже на рубе-

\footnotetext{
* При поддержке гранта GA ČR P406/12/1790 Staroslověnská lexikologie - nové př́spěvky ke staroslověnské lexikografii.

${ }^{1}$ Д. ИвановА-МирчевА, Ж. ИКономовА, Хомилията на Епифаний за слизането в ада: неизвестен старобългарски превод, София 1975. Более древний текст включен в Клоцов сборник и в Супрасльскую рукопись, младший в Германов сборник. Для дальнейшего исследования Варф будет очень важно языковое и лексическое сопоставление с этими памятниками.

${ }^{2}$ Этот апокриф дошел до нас в переводах с латинского и греческого языков. Список рукописей cf. в: A. De Santos Otero, Die handschriftliche Überlieferung der altslavischen Apokryphen, II, Berlin-New York 1981, p. 61-98.

${ }^{3}$ А. ВАСильЕВ, Anecdota graeco-byzantina, vol. I, Mosquae 1893, p. 10-23.
} 
же X-XI веков, содержит тексты глав 1,1-4,32. Кодекс, в котором находится этот список, называется Codex Hierosolymitanus Sabbaiticus 13 и хранится в Иерусалиме (далее Сабаит) ${ }^{4}$. В некоторых местах текст данной рукописи испорчен.

Старославянский перевод Варф дошел до нас в шести списках, четыре из которых принадлежат русской редакции старославянского языка и две сербской. Первым списком русской редакции является список Паисиевского сборника, созданного на рубеже XIV-XV веков и хранящегося в Российской национальной библиотеке в Санкт-Петербурге (Кир.-Бел. № 4/1081, далее Паис) ${ }^{5}$. Этот список содержит полный славянский текст памятника в рамках глав 1,1-4,13 и по сравнению с остальными списками показывает некоторые корректировки текста, сделанные, наверное, по поводу сборника, в который список включен. Второй список русской редакции восходит к началу XVII века, содержит только отрывки отдельных глав и хранится в собрании Уварова в Государственном историческом музее (ГИМ) в Москве (Увар. 884). Остальные два списка русской редакции содержат только первую главу и, по сравнению с двумя выше приведенными, являются более поздними экземплярами. Список из собрания Барсова в ГИМ был создан на рубеже XVII-XVIII веков (Барс. 2730, далее Барс), а список Государственного архива Тверской области - в XVIII веке (Ф. 1409. Оп. 3. Д. 25). Что касается двух сербских списков, более древним из них является список из сборника № 103 Дечанского монастыря середины XIV века' ${ }^{6}$ который содержит только стихи 1-23 первой главы памятника. Второй список сербской редакции содержит полный славянский текст. Он возник в XVI веке и хранится в Австрийской национальной библиотеке в Вене под шифром Cod. slav. 125 (далее ВенаСл) ${ }^{7}$.

Апокрифические тексты в славянской среде пользовались большой популярностью. Таких текстов до нас дошло много и можно сказать, что Варф из них никак не выделяются, так как представляют нейтральный старославянский язык и точно придерживаются греческого подлинника. Для определения места и времени создания первоначального перевода памятника на

\footnotetext{
${ }^{4}$ A. Wilmart, E. Tisserant, Fragments grecs et latins de l'Évangile de Barthelémy, RB 10, 1913, p. 181-190, 321-344.

${ }^{5}$ А.Н. Пыпин, Ложные и отреченные книги русской старины. Памятники старинной русской литературы, издаваемые грабом Григорием Кушелевым-Безбородко, vol. III, Санкт-Петербург 1862, p. 109-112; Н.С. ТихонРАвОв, Памятники отреченной русской литературы, vol. II, Москва 1863, p. 18-22.

${ }^{6}$ А. МилтеновА, За един неизвестен препис от апокрифните вбпроси и отговори на апостол Вартоломей, [in:] Пение мало Георгию: сборник в чест на 65-годиинината на проф. дфн Георги Попов, ed. М. ЙовчевА, София 2010, p. 464-477. Искренно благодарю А.А. Турилова за предоставление этого списка.

${ }^{7}$ В. Мочульский, Следы народной библии в славянской и древнерусской письменности, Одесса 1893, p. 276-281.
} 
старославянский язык, и его включения в славянскую переводческую литературу нужен подробный лексический анализ. Одну из частей такого анализа представляет исследование находящихся в тексте преславизмов, то есть языковых, в частности, лексических компонентов, типичных для преславской редакции старославянского языка, которая возникла в Преславской книжной школе во время правления царя Симеона в начале X века. Преславская книжная школа до сих пор изучена только в своих основных чер$\operatorname{Tax}^{8}$. Все исследование до сих пор основано на сравнении дошедших до нас рукописей отдельных библейских книг, у которых уже возможно почти убедительно определить, какую редакцию славянского перевода они содержат. В случае небиблейских книг эта убедительность снижается, потому что эти тексты очень разнообразны и использование в них преславизмов не всегда является явным доказательством их преславского происхождения. Несмотря на этот факт, анализ преславизмов все-таки оказывается важной частью исследования любого старославянского памятника и способствует хотя бы приблизительному определению места и времени его создания.

Особый пласт лексики старославянских памятников, тематически связанных со Священным писанием, представляют библейские цитаты или аллюзии ${ }^{9}$. Лексический анализ цитат может показать, какую редакцию библейских книг переводчик знал и использовал во время работы над первоначальным переводом памятника, и таким образом узнать время и место его создания.

В Варф 2,7 находится часть библейского стиха 1 Cor 11,3, в котором апостол Павел говорит, что голова всякого мужа - Христос, голова женщины - муж, а голова Христа - Бог. В Варф Богородица хочет этим стихом убедить апостолов, чтобы они на молитве стояли перед ней, а не за ней. В грече-

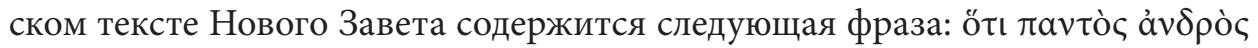

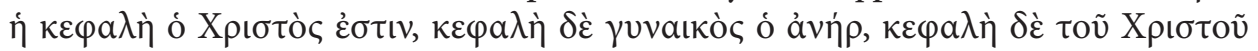

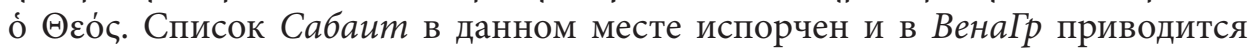

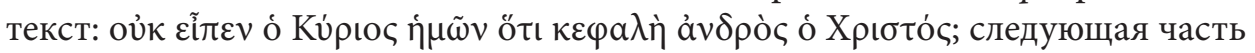
стиха отсутствует. В архаической редакции старославянского перевода книги Апостол, которую представляет, напр., Церколезский Апостол первой по-

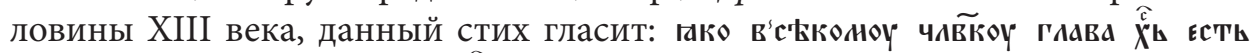

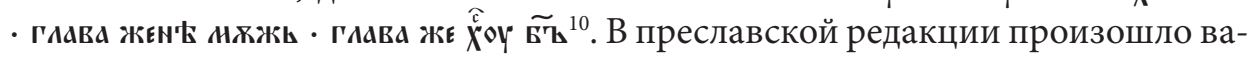
рьирование перевода: греческое существительное ó åví $\rho$, в контексте приведенного стиха, на месте архаического члювък' было заменено семантически

\footnotetext{
${ }^{8}$ До сих пор наиболее полная работа о преславизмах: Т. СлАвовА, Преславска редакция на Кирило-Методиевия старобългарски евангелски превод, КМс 6, 1989, р. 15-129.

9 Библейским цитатам в Варф будет посвящена самостоятельная статья в журнале „Slavia“. Поэтому здесь не будем вдаваться в подробности и материал представим только в основных чертах. ${ }^{10}$ Д. БогДАНОвИЧ, Б. ВЕЛЧЕвА, А. НАумов, Болгарский апостол ХІІІ века: рукопись ДечаниЦрколез 2, София 1986. Искренно благодарю Ш. Пилата за предоставление снимков рукописи.
} 
более совпадающим - жжжь ${ }^{11}$, как доказывает, напр., Толстовский Апостол $\mathrm{XIV}$ века ${ }^{12}$. Этот вариант находим и в обеих славянских списках Варф, содержащих главу 2,7: ғако ноүж8 глава єсть $\widetilde{\boldsymbol{x}}$ (по ВенаСл). Список Паис содержит еще дополнение по подлинному библейскому стиху: а жєм' мүжь.

В Варб также 4 раза (главы 2,2, 2,4, 2,18, 4,2) содержится упоминание

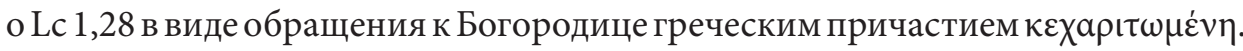
В архаической редакции евангелий мы находим перевод влагодатьната/ влагод'Етьнағ, который в преславской редакции был заменен причастием оврадованага ${ }^{13}$. Интересно, что в списке ВенаСл приведенное причастие в двух местах пропущено: в стихе 2,2 находим только въпрашантє в отличие от тек-

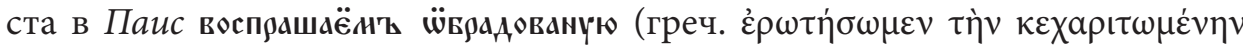

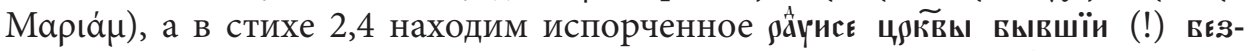

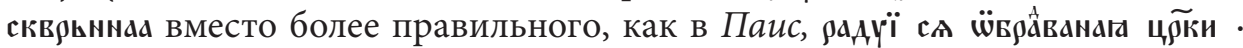

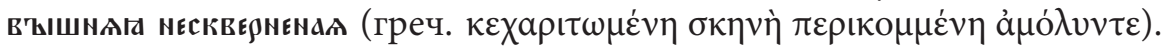

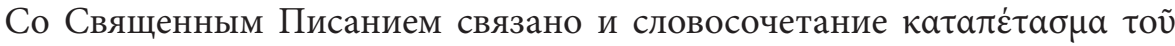
vaoũ, с которым встречаемся в Новом Завете в стихах Mt 27,51, а также в Mc 15,38, Lc 23,5, Неb 6,19 и 9,3. В Вар $\varnothing$ данное словосочетание переводится зав'кса цегковнаға и встречается в главе 1,27 , когда Иисус повествует апостолам об ангеле мести, из рук которого выходящее пламя уничтожит еврейский храм и разорвет его завесу. Хотя к приведенному стиху у нас нет соответствующей греческой версии (список ВенаГр начинается только с главы 1,28, а Сaбаит здесь испорчен), учитывая дословность славянского перевода, можно предположить, что греческая версия не отличалась от новозаветного стиха.

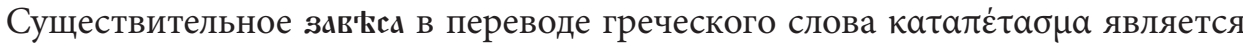
преславизмом, как, впрочем, и вариант опона, которые оба заменили архаический перевод - катапєтазна ${ }^{14}$. Для дальнейшего исследования Варф является интересным тот факт, что лексема зав'кс (црьковнаґ) присутствует в Евангелии Никодима, которое описывает похожий сюжет.

В лексике, помимо библейских цитат и аллюзий, можно заметить несколько тенденций, которые исследователи определяют как преславские. К ним относится стремление к замене словосочетаний одним словом, в $В a p \oint$, например, в главе 1,6, когда Варфоломей говорит Иисусу, что когда того повесили на кресте, Варфоломей следовал за ним неподалеку и увидел, как ангелы спускаются с небес и кланяются ему. В списке ВенаСл упо-

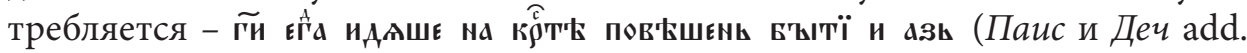

\footnotetext{
${ }^{11}$ И. ХриСтовА-ШомовА, Служебният Апостол в славянската ръкописна традиция, София 2004, p. 767.

${ }^{12}$ Ibidem, p. 230. Толстовский Апостол является типическим представителем преславской редакции старославянского перевода книги Апостол.

${ }^{13}$ А.С. НовиковА, Преславская редакция евангелия, [in:] Славянское и балканское языкознание. Палеославистика: слово и текст, еd. В.С. ЕФимовА, Москва 2012, р. 160-161.

${ }^{14}$ Т. СлАвовА, op. cit., p. 62-63.
} 


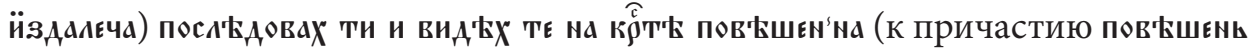

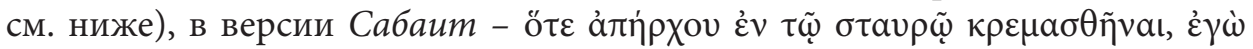

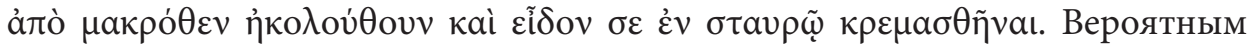

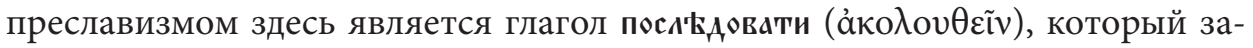
менил архаическое сочетание ити по көнь или вслtды көго. Однако в одном

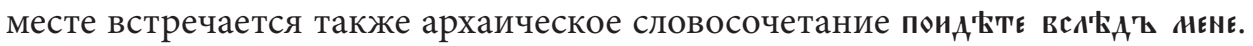
Это можно найти в Варф, глава 3,5, где Иисус ведет апостолов к апокалип-

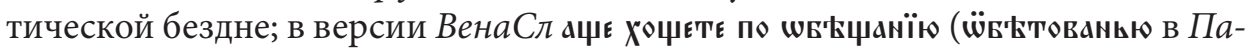

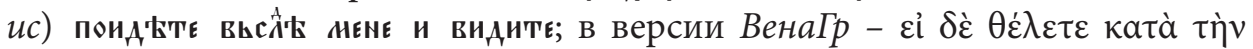

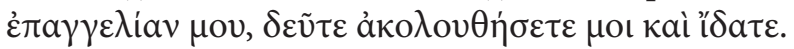

Вторая тенденция состоит в частом использовании прилагательных с приставкой пюћ- имеющей усилительное значение. В Варф такую тенденцию встречаем, например, несколько раз в употреблении прилагательного пюКвєликъ ${ }^{15}$ (вместо греческих находится, в рамках канонических старославянских памятников, только

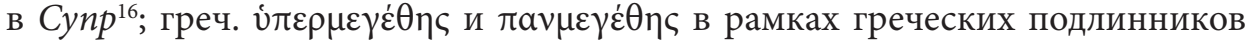
старославянских памятников не имеется ${ }^{17}$. Приведенное прилагательное находим в списках ВенаСл, Деч и Барс в главе Варф 1,21, когда Варфоломей спрашивает Иисуса о превеликом человеке Адаме, а в списке Паис на данном месте приводится описательная форма - вєлик' зєль. Остальные 4 примера можно найти только во второй главе. Два первых в молитве Бо-

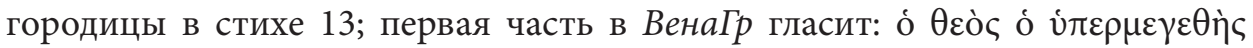

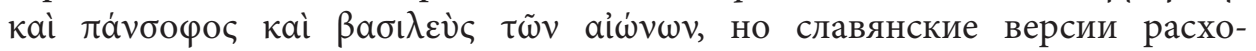

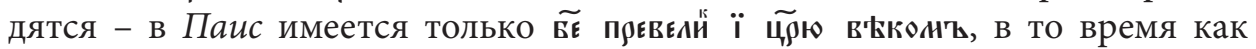

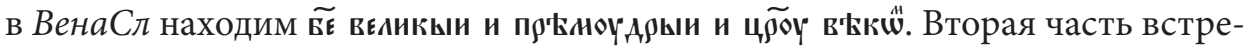

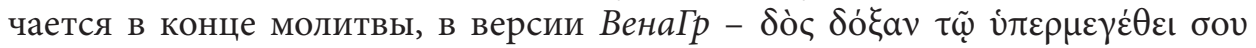

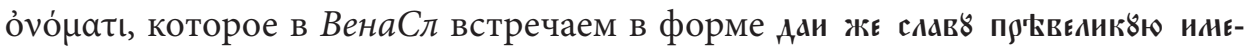
ны твоєн8, затем что в Паис имеется более Правильное - даї жє славу їнАни своёну · прєвєликону. Два раза находится это прилагательное на месте, где Богородица описывает свидание с Богом, который угостил ее превеликим хлебом и превеликой чашей вина. Славянские версии ближе к списку Сабаuт,

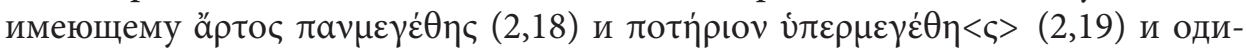

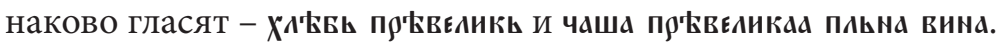

\footnotetext{
${ }^{15}$ P.М. ЦЕйтлин, Старославянские прилагательные с приставкой прп-, [in:] Studia palaeoslovenica, ed. M. Bauerová, M. ŠTĚrbovÁ, Praha 1971, p. 66.

16 Просмотрено во втором, исправленном и дополненном издании Старославянского словаря по рукописям X-XI веков, которое готовится под руководством Эмилии Благовой в Отделе палеославистики и византологоии Славянского института Академии наук Чешской Республики. Словарь первоначально издан в Москве в 1994 году под редакцией Р.М. Цейтлин, Р. Вечерки и Э. Благовой.

17 Просмотрено в греческо-старославянской картотеке Отдела палеославистики и византологии Славянского института Академии наук Чешской Республики.
} 
Интересное разночтение приносит выше указанная глава 1,6. В предложении два раза употребляется греческий инф. аор. крєнабӨп̃vaı (от глагола

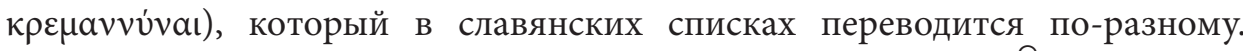

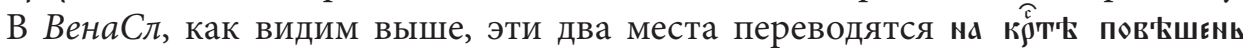

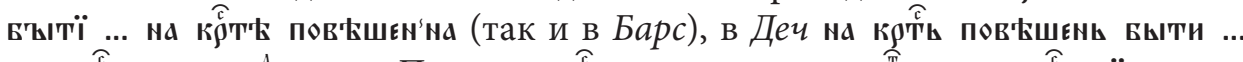

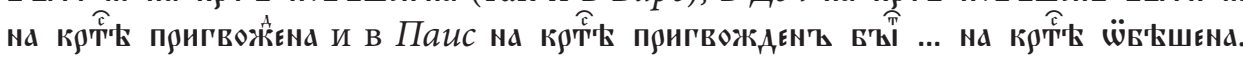

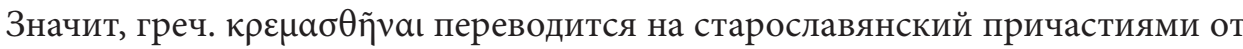

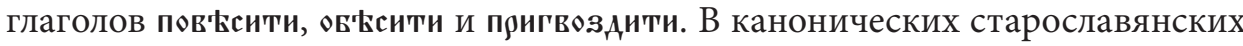
памятниках можно встретиться с этими тремя глаголами, но в случае

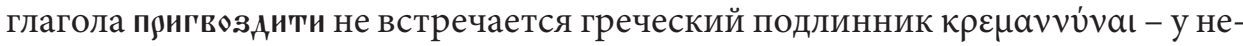
го немножко другой семантический оттенок. В значении распятия на кресте, вероятно, глагол ов ксити является архаизмом, который в Преславской школе был заменен формой пов'ситт. Варьирование трех глаголов в данном месте в Вар $\oint$ остается неясным, но можно предположить, что использование определенного конкретного глагола является только стилистическим

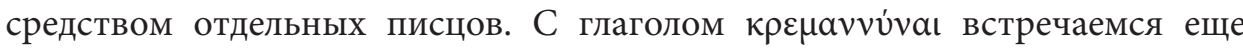
в главе 1,22 , но здесь все списки используют формы того же глагола пов'скити.

В главе 4,12 описывающей связанного Сатану, употребляется слово-

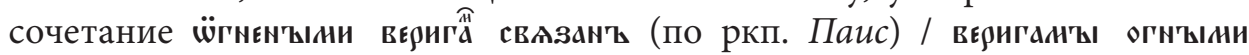
свєзан'ы (по ВенаСл), в греческой версии - лvрі

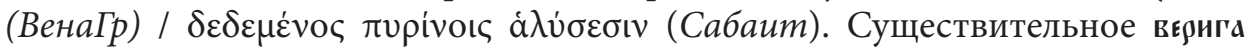
на месте греческого ö $\lambda$ бı является преславским вариантом архаического словосочетания жжє жєк'ъьннюе ${ }^{18}$.

К вероятным преславизмам относится и прилагательное А'Ев вместо

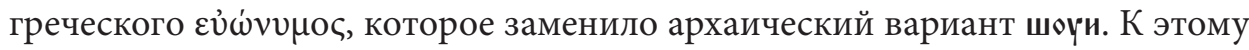
прилагательному как к преславизму надо относиться осторожно, потому что вскоре оно зафиксировалось во всех славянских языках и таким образом могло использоваться не только в преславской редакции. В Вар $б$ встречаем его в вышеупомянутой главе 1,19 , когда Бог принимает Богородицу в церкви. Превеликий хлеб появляется, когда Бог махнет правой стороной своей

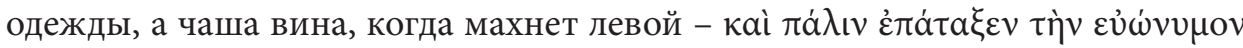

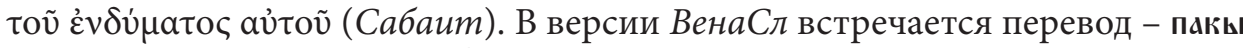

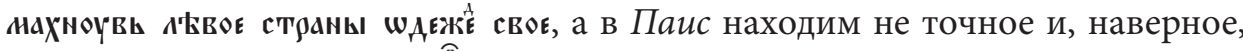

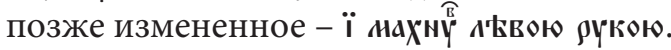

Из отдельных лексических преславизмов можно далее привести, напр., глагол оүжасати с⿱㇒⿴囗十 вместо дивити $\mathfrak{c}$ в в Варф 1,16 (в данном случае нет греческого подлинника), или наречие т"ъчинх вместо архаического түък'ыно на месте греческого нóvov. Это наречие употребляется, например, в главе 1,7 и списки приводят интересные разночтения - в Паис и Деч имеется тъъчиюж, а в ВенаСл и Барс - тъқкъно. В рассмотренном нами лексическом

${ }^{18}$ И. ХРИСТОвА-ШомовА, op. cit., p. 230. 
материале это второй пример, когда сербский список ВенаСл и русский Барс приводят те же варианты по сравнению с остальными списками, но для окончательного определения их взаимоотношения необходимо провести дальнейшие исследования.

Кроме очевидных преславизмов в тексте Варф находятся также архаические лексемы. Их употребление во всех списках Варф показывает, что, по всей вероятности, эти лексемы присутствовали в тексте уже в первоначальном переводе памятника и не являются более поздними намеренными архаизмами. Например, въскрьскнию (Варб 1,1) вместо

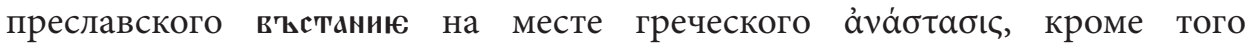
существительное жюьтва (Варф 1,28, 1,29 и два раза в 1,31) вместо

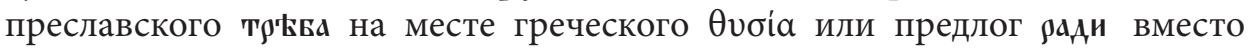

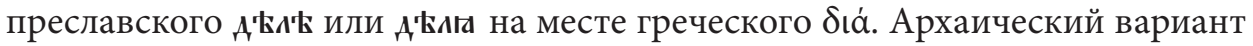
послелога встречается в Варф 1,22 в списках ВенаСл, Деч, Барс, но в Паис находится $\mathbf{A} \mathbf{\mathbf { k }} \mathbf{\mathrm { t }}$, которое несомненно является поздней поправкой.

На основе выше приведенного лексического анализа можно сделать вывод, что славянский перевод Варф, по всей вероятности, является болгарским, и мог возникнуть во время существования Преславской книжной школы в Х веке. Возможно привести два варианта датировки. Во-первых, это может быть старый преславский перевод начала X века, когда преславизмы не были устойчивы и использовались еще некоторые архаические лексемы. Во вторых, это может быть и поздний преславский перевод, возникший в одном из специфических центров Преславской школы, которые имели собственные традиции в использовании преславизмов и архаической лексики. Для подтверждения приведенной датировки перевода необходимо провести дополнительные анализы - лексические и синтаксические, а также сравнить текст с тематически похожими старославянскими памятниками. В заключение отметим, что наш анализ преславизмов является первым шагом к комплексному исследованию Варф.

\footnotetext{
Abstract. Preslavisms in the Apocryphal Questions of Bartholomew. Paper deals with the lexical analysis of the Old Church Slavonic version of the Apocryphal Questions of Bartholomew, a literary monument written most likely in Greek in the $3^{\text {rd }}$ century. The analysis shows that the Slavonic version contains not only lexical elements typical for the Preslav redaction, but also some archaic figures. This leads to the conclusion, that the primal Old Church Slavonic translation may be made in Bulgaria in the $10^{\text {th }}$ century. There are two possibilities of a more exact dating. The text may have been translated in the early $10^{\text {th }}$ century when the lexical elements of the Preslav redaction weren't strictly used yet and still there occurred many archaic figures. The second possibility is that the translation was made later in the $10^{\text {th }}$ century in one of the distant centers of the Preslav literary school, in which a specific tradition in using Preslav and archaic lexical elements was held. However, a further lexical and language analysis is needed for the confirmation of the stated dating.
} 
Ключевые слова: Вопросы апостола Варфоломея, лексический анализ, преславизмы, старославянский язык.

Keywords: Questions of Bartholomew, Lexical analysis, Preslavisms, Old Church Slavonic.

Martina Chromá Slovanský ústav AV ČR, v. v. i.

Valentinská 1

11000 Praha 1

chroma@slu.cas.cz 